\title{
SITUACIÓN Y DESAFÍOS DE LA FORMACIÓN Y CAPACITACIÓN DE DOCENTES ${ }^{1}$
}

\author{
Vilmar Alves Pereira ${ }^{2}$
}

\begin{abstract}
Resumen: Este artículo fue producido a partir de mi participación en el III Foro Internacional de Formación y Desarrollo Docente desde "la innovación y creatividad para la educación integral y de calidad", organizado por el Ministerio de Educación de Nicaragua - MINED- en la ciudad de Managua. De esta forma, el trabajo que aquí presento en forma de narrativa discute los desafíos de la formación docente en torno de la siguiente sistematización: en un primer momento establezco problematizaciones sobre el contexto actual y la lógica neoliberal en la educación. Aproximo a esa problematización más cuestionamientos sobre la formación política del educador popular y los compromisos que conlleva; un segundo momento, presento fundamentos teóricos sobre el paradigma de Educación que está internalizado en nuestra trayectorias formativas y nuestra constitución docente (Paradigma Positivista); en el tercero presento desafíos de la formación docente teniendo por referencia el contexto actual brasileño de golpe político con sus implicancias directas de encogimiento de derechos en la educación y el contexto nicaragüense de ampliación de derecho a la educación, de protagonismo de los sujetos y de abertura democrática en el sentido de las posibilidades de una educación libertadora.
\end{abstract}

Palabras clave: Desafíos. Formación. Docentes. Nicaragua.

\section{SITUAÇÃO E DESAFIOS DA FORMAÇÃO E CAPACITAÇÃO DE DOCENTES}

Resumo: Este artigo foi produzido por ocasião da participação no III Foro Internacional de Formación y Desarrollo Docente desde "la innovación y creatividad para la educación integral y de calidad", organizado pelo Ministério da Educação da Nicarágua - Mined- na cidade de Manágua. Dessa

1 Traducción: MsC. Cristian Danilo Cerda - Ministerio de Educación Nicaragua.

2 Filósofo. Maestro Doctor en Educación, Educador Popular e Ambiental. Coordinador del Programa de Post grado en Educación Ambiental de la Universidad Federal de Rio Grande (FURG); Profesor e investigador en el Instituto de Educación y en los Programas de Educación (PPGEDU) y Educación Ambiental (PPGEA) da Universidad Federal do Rio GrandeFURG. Editor de la Revista Electrónica de la Maestría en Educación Ambiental -REMEA. vilmar1972@gmail.com 
forma, o trabalho que aqui apresento em forma de narrativa discute os desafios da formação docente a partir da seguinte sistematização: num primeiro momento estabeleço problematizaçôes sobre o contexto atual e a lógica neoliberal na educação. Associo a essa problematização mais questionamentos sobre a formação política do educador popular e os compromissos que dela decorre; Num segundo, apresento fundamentos teóricos sobre o paradigma de educação que está internalizado em nossas trajetórias formativas e nossa constituição docente (Paradigma Positivista); num terceiro apresento desafios à formação docente tendo por referência o contexto atual brasileiro de golpe político com suas implicância diretas de encolhimento de direitos na educaçáa e o contexto da Nicarágua de ampliação do direito a educação, de protagonismo dos sujeitos e de abertura democrática no sentido das possibilidades de uma educaçáo emancipadora.

Palavras-chave: Desafios. Formação. Docentes. Nicarágua.

Es ambición de nuestra pedagogía que los estudiantes tengan acceso a contenidos verdaderos y que, al mismo tiempo, los intereses sean sentidos como un apoyo en su propio esfuerzo para que vivan y conozcan. Y entonces el profesor ha de parecerles también una instancia que ayuda y no una potencia hostil. $^{3}$

\section{DE LA PROBLEMATIZACIÓN DEL CONTEXTO ACTUAL Y LA LÓGICA NEOLIBERAL.}

Todo acto pedagógico no ocurre en un vacio y, por tanto, se constituye en un acto político que posee una teoría que fundamenta mi forma de ser profesor o educador.

Partiendo de la comprensión que no existe neutralidad en el acto educativo hago una invitación a usted profesora-educadora, profesor-educador. Se trata de una invitación afectiva que tiene una intención clara de promover cambios en nuestra forma de ser, de pensar y de vivir la educación. Estudios en el campo del psicoanálisis afirman algo muy importante que nadie cambia aquello que antes no interiorizó. De esa manera te invito a reflexionar conmigo sobre ¿Cuál es el paradigma que está interiorizado en su trayectoria formativa? ¿Usted lo conoce? Afirmo esto partiendo de la constatación frecuente que cuando vamos donde un médico especialista, por ejemplo, nosotros escogemos cuidadosamente y hasta investigamos sobre su especialidad. Sin embargo, cuando preguntamos a los docentes cual es la metodología y la epistemología que orientan su acción pedagógica expresan la respuesta siguiente: "yo utilizo todas". ¿Usted correría el riesgo de someterse a una cirugia con quien aplica todas las metodologías?

Asociado a esa problematización inicial, como soy filósofo, siento la necesidad de problematizar algunas terminologías que frecuentemente llegan hasta nosotros através del horizonte neoliberal. Traigo estas cuestiones a partir de experiencias vividas en Brasil y a partir de estudios realizados que constatan como, a partir de

3 SNYDERS, Georges apud LIBÂNEO. Democratização da escola pública. 1985.p.13-14. (Traducción propia) 
la década de 1990, las políticas neoliberales interfieren directamente en nuestra vida atribuyendo sentidos e interfiriendo en nuestros valores. Se trata de una lógica hegemónica principalmente oriunda de los Estados Unidos da América sobre los pueblos de Latinoamérica. Creo que ese "canto de la sirena" posee una racionalidad clara dirigida para fines muy claros, que debemos saber: el dominio, el lucro y el poder. Para ellos no es importante que nosotros tengamos identidad, sentido de pertenencia y valores propios de nuestras vivencias. Para ellos es importante que todos entonemos el mismo himno.

De este modo, continúo problematizando: ¿Quién soy yo en mi docencia? ¿Un facilitador o un problematizador? ¿Existe diferencia entre facilitar y problematizar? Y no que se refiere a las constantes invitaciones: ¿Qué significa educar para emprender? ¿ De dónde viene esa matriz emprendedora? Otra cuestión: "tenemos que educar para el mercado de trabajo". Pregunto: ¿Existe diferencias entre educar para el mercado de trabajo o educar para el mundo del trabajo? Lo mismo puede ocurrir en relación, por ejemplo, al desarrollo sostenible. ¿Qué sostenibilidad es esa? ¿Económica o socio ambiental? Y la innovación ¿Qué significa? Innovar para cambiar apenas la forma, innovar para emprender financieramente o innovar para la creatividad. Y el debate tan acogido en América Latina sobre educar por competencia y habilidades apuntando la excelencia. ¿Quién ambiciona ese sujeto competente? ¿Qué mercado es ese para ese sujeto hábil? ¿Qué habilidades es esa? ¿Qué discurso de excelencia es ese? ¿Meritocrático? ¿O excelencia en las relaciones socioculturales que valoricen nuestro protagonismo? Lo mismo puede ocurrir con la idea esencialista de talento: ¿las personas poseen talento o potencialidades? Hago esa problematización no con intuito de agotarlas preguntas, más al contrario para que podamos reflexionar sobre el uso de expresiones que llegan hasta nosotros por direccionamiento del paradigma neoliberal. En mi comprensión necesitamos tener cierto cuidado para no caernos en una perspectiva que reproduzca y que refuerce apenas ese discurso.

Es este tiempo presente, que fundamental percibimos de qué lado estamos: con los diferentes o con los antagónicos. Son tiempos de reflexiones profundas sobre la forma como conducimos nuestras prácticas en los diferentes campos de acción. Son tiempos de reevaluarnos nuestro pasado de actuar de modo contundente en favor de una sociedad bumanizadora y libertadora.

En lugar del "canto de la sirena" de la educación emprendedora, de las nuevas alianzas con el sector privado con su racionalidad estratégica dirigida a fines donde el lucro y el poder son los direccionamientos. Creo sí en la educación popular libertadora y consecuentemente bumanizadora.

Teniendo la clareza sobre el lado que asumimos y el horizonte que buscamos y poder vivenciar la Educación, habrá aún algunas otras preguntas que considero fundamentales sobre mi identidad o sobre a mi ontología como profesor (a) que soy o que me estoy constituyendo. Particularmente, esas preguntas me han ayudado a reflexionar y posicionarme por el horizonte da educación popular. Preguntas que deberíamos hacer siempre en la escuela. Ellas deben estar en el debate y que surgen 
desde la construcción del Proyecto Político Pedagógico de la escuela. En general esas cuestiones refuerzan que todo acto pedagógico es también político por eso como punto de partida es necesario que podamos reflexionar:

¿Qué sujetos queremos formar? ¿Qué saberes queremos discutir? ¿QQué sociedad queremos para vivir? ¿Qué escuela queremos? ¿Qué educación queremos priorizar? ¿Qué evaluación necesitamos construir? ¿Qué cultura queremos valorizar? ¿Qué conocimiento queremos trabajar? ¿Qué relaciones de poder queremos mantener? (PASSOS, 1995, p.15 traducción propia).

Aun problematizando aumentamos otras preguntas que tratan sobre nuestra dificultad cuando trabajamos colectivamente. Ellas se refieren a la constatación de que tenemos un currículo fragmentado y tenemos enormes dificultades de trabajar en una perspectiva interdisciplinar y de formación integral. ¿De dónde viene esa dificultad? ¿En qué momento nos fragmentamos?

En mi comprensión ese amplio conjunto de preguntas debe servir para reflexionar sobre nuestra identidad, sobre nuestra trayectoria formativa y sobre las opciones que debemos hacer una vez, como afirma (Freire 2000, p.66): "Saber que no puedo pasar desapercibido por los estudiantes, y que la manera como me perciben me ayuda o desayuda en el cumplimento de mi tarea de profesor, aumenta los cuidados con mi desempeño. Simi opción es democrática, progresista, no puedo tener una práctica reaccionaria, autoritaria, elitista. No puedo discriminar a los estudiantes en nombre de ningún motivo. La percepción que el alumno tiene de mí no resulta exclusivamente de como actúo, también de como el alumno entiende como actúo. Debo estar atento a la lectura que hacen los estudiantes de mi actividad con ellos".

\section{DE LA FUNDAMENTACION E IDENTIFICACIÓN DEL PARADIGMA FORMATIVO POSITIVISTA.}

El debate sobre formación integral no es un debate actual. Consiste en una exigencia y necesidad actual. Si estudiáramos la historia del pensamiento educativo en el occidente veremos que hubo momentos en que la formación integral ya existía a partir de concepciones educativas que daban cuenta de una amplia concepción de formación. En ese sentido destaco algunos: el modelo de formación de la Paideia ${ }^{4}$ n

4 Paidéia es uno de los legados inmortales de la mentalidad griega. Ella abarca el concepto de formación moral, física, poética y teológica del hombre de la Antigüedad. La Paidéia tal cual los griegos entendian, envuelve la enseñanza del Cuerpo y de la mente. Poesia, teologia, filosofía, gramática, retórica, matemática, música e astronomia faziam parte da formação da alma do homem grego. 
la Grecia Antigua, el sistema de enseñanza de las artes liberales en la edad media através del trivium e quadrivium ${ }^{5}$ e Bildung ${ }^{6}$ en la modernidad.

Más si el conocimiento no era trabajado de forma fragmentada es normal que cuestionemos: ¿de dónde vino esa separación? ¿Cuántos años tiene? Así paso a defender ahora que hay un paradigma predominantemente interiozado en nuestro proceso formativo y consecuentemente en nuestra constitución docente. Él es conocido por paradigma positivista.

Desarrollado por Auguste Comte (1798-1857) el positivismo, en el siglo XIX, parte de la tentativa de responder una pregunta fundamental: ¿Cómo es posible al ser humano reformular la sociedad, alcanzar la evolución de la humanidad y también la finalidad última de ser feliz? Teniendo por referencia esa inquietud Comte evaluó la historia del pensamiento en el occidente y demostró que, en varios momentos y etapas, se buscó esa felicidad y no se consiguió. Analizó la historia a través de sus prácticas evolutivas, teológicas y metafísicas y percibió en ambos que no alcanzaban los fines últimos porque cuando uno se centra en los aspectos de las creencias el otro queda en el campo de lo abstracto. En su comprensión era necesario una ciencia que tuviera resultados precisos y seguros. Percibió que la felicidad y el progreso deberían acontecer en el paradigma positivo, que conocemos hoy por epistemología o modelo positivista. Es importante resaltar que el estado positivo, en la comprensión de Comte es como sinónimo de estado científico como una fuerte apuesta en la ciencia y en el método científico moderno que vino desde Galileo Galilei, Francis Bacon y René Descartes. Es el clásico método que hasta hoy es utilizado que parte de enunciados, después sigue para una observación, levantamiento de hipótesis, verificación, prueba de hipótesis y búsqueda de resultados.

Asociado a ese método el paradigma positivista tiene muchas características que aún hoy son identificadas por estar enraizadas fuertemente en muchos campos de saber principalmente en la educación, como modelo en estos últimos doscientos años.

5 O Trivium, lógica, gramática y retórica, abarcaba el ámbito del lenguaje desarrollada por los hombres desde el raciocinio lógico-dialéctico hasta el método gramatical (entonación, contacto con poemas épicos, fábulas, texto de oradores, etc.). Ya el Quadrivium daba continuidad a esos estudios, disponibilizando al estudiante herramientas para entender la organización del mundo natural e la simbólica de los números. Las formas geométricas, los cálculos (teoremas, etc.) de fenómenos del mundo físico e astronómico, bien como el conocimiento de las siete notas musicales, eran estudiados por las disciplinas del Quadrivium.

6 El concepto de Bildung (...) es, sin duda alguna, la idea más importante del siglo XVIII y es precisamente ese concepto que designa el elemento aglutinador de las ciencias del espíritu do siglo XIX. (...) el concepto de Bildung torna evidente la profunda transformación espiritual que hizo del siglo de Goethe aun uno nuestro contemporaneo, al paso que el del Barroco nos sea hoy como antigüedad histórica. En esa época, los conceptos y términos decisivos con los cuales aún hoy operamos adquieren su significado. (Apud BERMAN. Bildung et Bildungsroman, p. 141.) 
Algunas características de ese paradigma fácilmente identificada: usa el método de las ciencias exactas como ya se mencionó, confía demasiadamente en los números por considerar que ellos representan o se aproximan mucho más de la verdad, por lo tanto, configuran fuente de seguridad y también consideran que nuestra acción es neutra en la relación con los otros.

Ese modelo también desarrolla una relación denominada sujeto - objeto. El sujeto siempre es activo (aquel que reúne en si las condiciones de definir las realidades) y el objeto pasivo que aguarda acción del sujeto. Aquí podríamos hacer una aproximación con el modelo de profesor tradicional y su educación bancaria que conforme a Paulo Freire objetiva a sus estudiantes como:
"vasijas", en recipientes a ser "llenados" por el educador (...) en lugar de comunicarse el profesor hace "comunicados" y depósitos que los estudiantes reciben pacientemente, memorizan y repiten para guardarlos y archivarlos. (FREIRE 2011, p.80-81 traducción propia).

Prosigo con algunos otros ejemplos enraizados de esa matriz que refuerzan la dependencia que enfría las relaciones en nombre de una potente idea de neutralidad. Recuerdo que en mi infancia cuando el profesor pasaba asistencia el $\mathrm{N}^{\circ}$ decía mi nombre, muchas veces decía el número de matrícula. Comenzaba la asistencia por el número 1 hasta el número 30, por ejemplo. Pregunto a cada uno; si eso no ocurrió con ustedes que están leyendo este texto en este momento. Si eso ocurrió nos estamos identificando. En esa perspectiva el referido paradigma cree que es más fácil evaluar un número que a una persona. Es de cierta manera la lógica que impera en las empresas.

Dudo o cuestiono quien no tiene o nunca tuvo como referencia en su vida un número. Fui vendedor de electrodoméstico mi numero era 501098, si no alcanzaba la meta en las ventas, ya sabía que era el próximo a ser despedido. Siempre me cuestioné que es mucho más fácil cuantificar, es mucho más fácil medir y evaluar un objeto. Pero es allí que surgen las preguntas centrales: ¿Quiénes somos? ¿Sujetos u objetos?

En esa misma perspectiva muchas veces me quedo pensando sobre nuestra capacidad para evaluar a una persona. A veces parece que somos personas trascendentales y metafísicas que conseguimos medir el momento exacto que un ser humano es definido con un promedio de 59.9 y no 60.¿Qué capacidad nosotros tenemos de medir exactamente ese momento de 59 ? y aún encontramos argumentos y justificamos: si es 59.9, porque es el resultado de un proceso. Confieso que con todos mis estudios aún no consigo llegar ni desarrollar mi capacidad de medir a través de una lógica de precisión. El método positivista cuantifica.

Apuesto que cada uno de nosotros tenemos un número de matrícula en la nómina del Ministerio, el mío es de 1562383, ese número es mi referencia como docente en la universidad en que trabajo. Hace poco tempo atrás, un profesor, que vivió su vida entera en mi universidad y se jubiló cierto día fue a la biblioteca para recordar sus viejos tempos, fue a uno de los estantes escogió varios libros y cuando 
fue a retirarlos la joven que atendió dijo: "Señor no puede llevar los libros pues su número de trabajador es inactivo"

Cuanta tristeza sintió ese profesor, pues por no estar activo no pudo leer los libros. La sociedad positivista mide a las personas, cuantifica, diagnostica, y afirma que no se trata de ninguna relación que desarrolla subjetividad y que por tanto es neutra.

Ese paradigma formativo está muy presente en el contexto educativo actual. De modo general él ofrece resultados, índices, juicios, cuantificaciones y dice que la ciencia no desarrolla relaciones personales.

Augusto Comte, el creador del positivismo fue quien dividió el conocimiento en disciplinas. Hasta el siglo XIX no había disciplinas, pero si campos del saber. La disciplinaridad nos separa y cada uno de nosotros queda especialista. Vemos la parte, pero no vemos el todo. Eso dificulta nuestras relaciones en la escuela, dificulta también las relaciones intersubjetivas:

Figura 1- Enfoque disciplinar

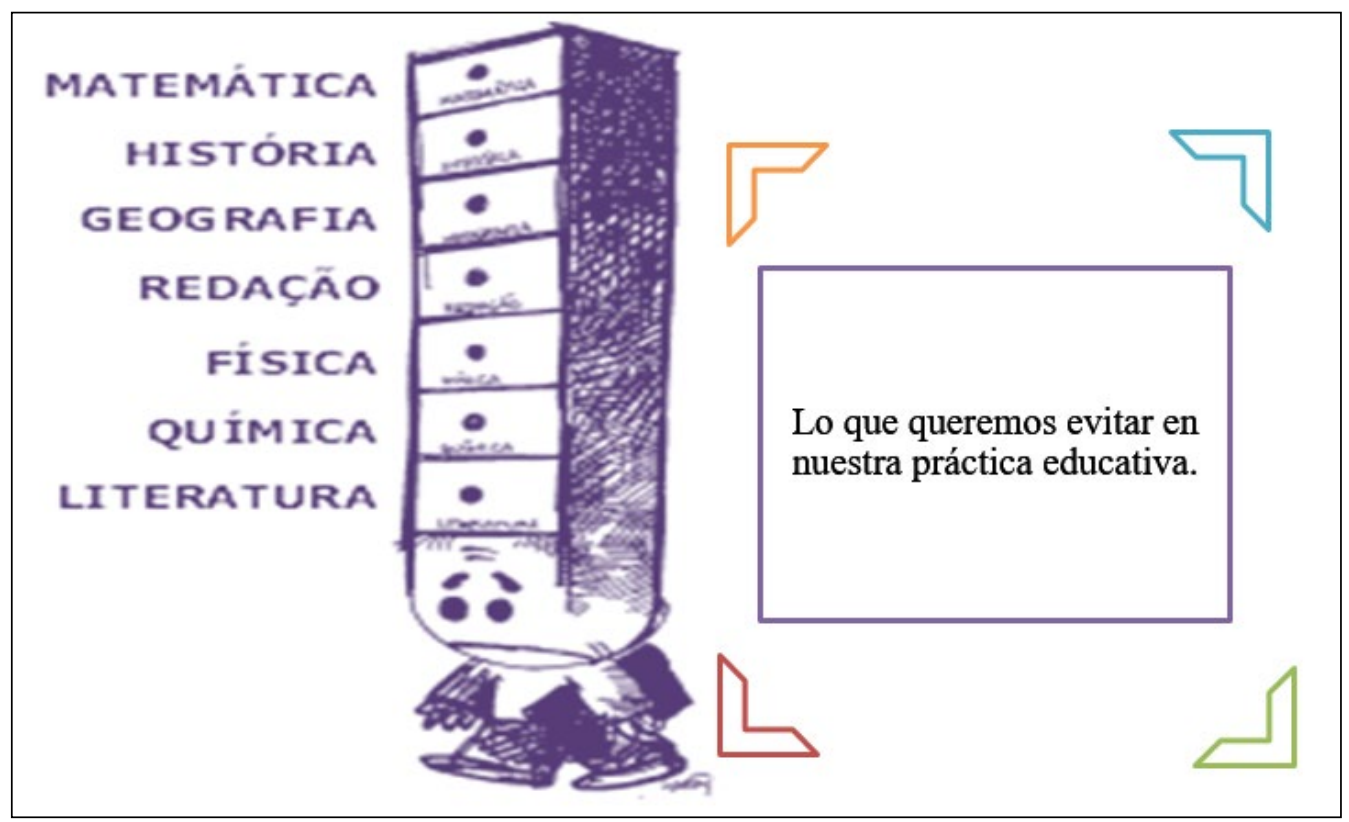

Presento ahora, resultados de modelos epistemológicos y pedagógicos conforme Becker (1993), con sus consecuencias en las relaciones de enseñanza y de aprendizajes. El primero tiene papeles claros, el profesor en la cima de la pirámide él es un sujeto, el estudiante abajo es el objeto y el medio no tiene importancia. En este paradigma no necesito saber quiénes son mis estudiantes, de donde vienen, pero es importante que los estudiantes bailen al son de la música. El profesor es el sujeto y la pedagogía que resulta de ese proceso Tradicional - directiva se presenta en la figura que se muestra a continuación. 
Figura 2- Pedagogía Tradicional-Directiva

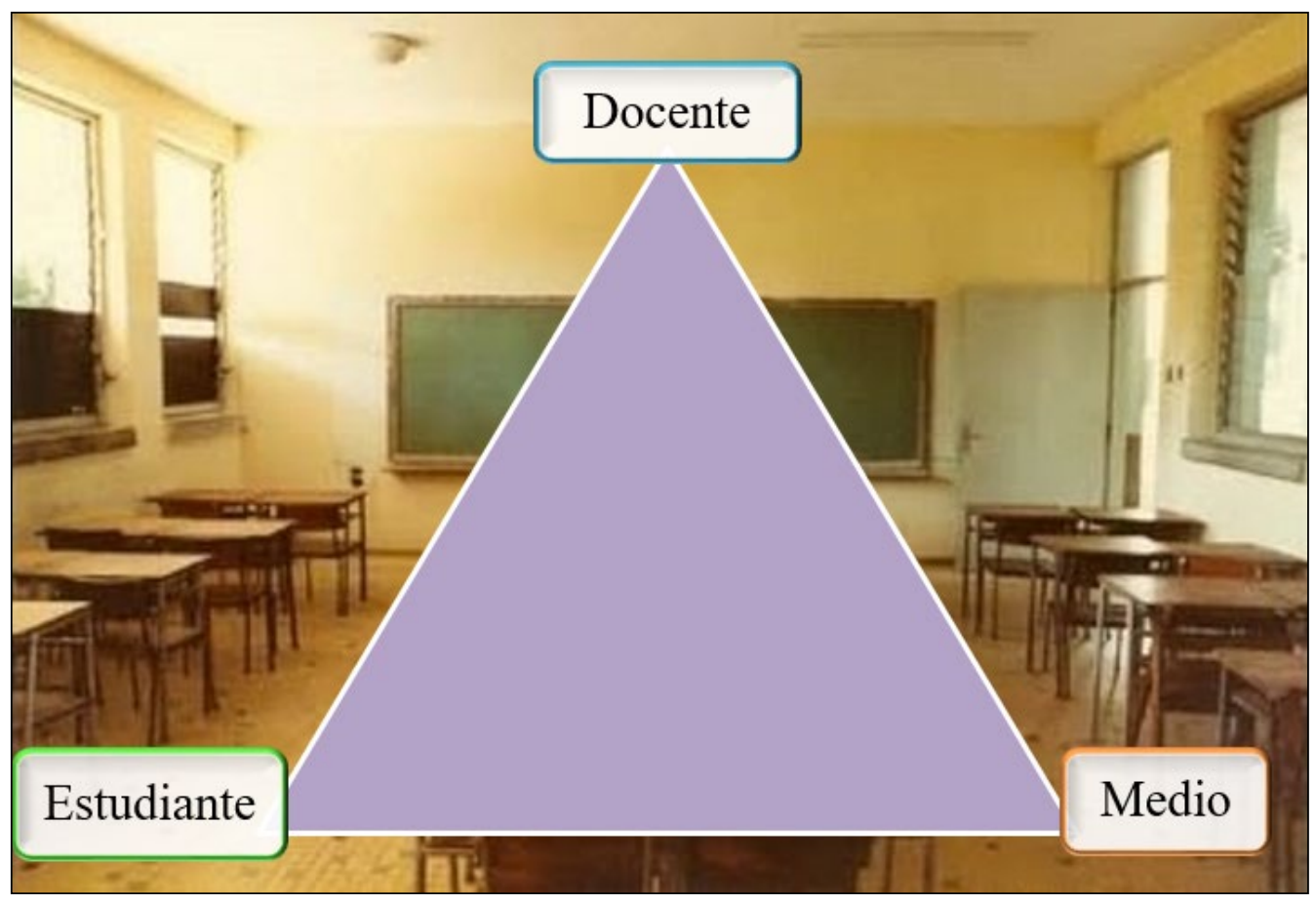

De acuerdo con el investigador brasileño Saviani (1999), después del siglo XVIII se desarrolló un modelo que apenas invirtió los papeles en esa relación. Por eso en mi comprensión, no basta apenas invertir los papeles en esa relación, porque apenas cambia la forma, pero las relaciones permanecen igual.

A partir de estudios de psicología de la educación, del pensador Carl Rogers, (1902-1987), hubo un cambio y se creó otro modelo que colocó al estudiante en la cima o centro y de esa forma surgieron varios problemas como la indisciplina, por ejemplo. El primer modelo era disciplinar y autoritario, el segundo modelo coloca al estudiante en el centro y el profesor pasa a ser facilitador que queda apenas acompañando el proceso el proceso de aprendizaje, y el medio gana relevancia, veamos a continuación la lámina. 
Figura 3- Pedagogia Liberal no directiva.

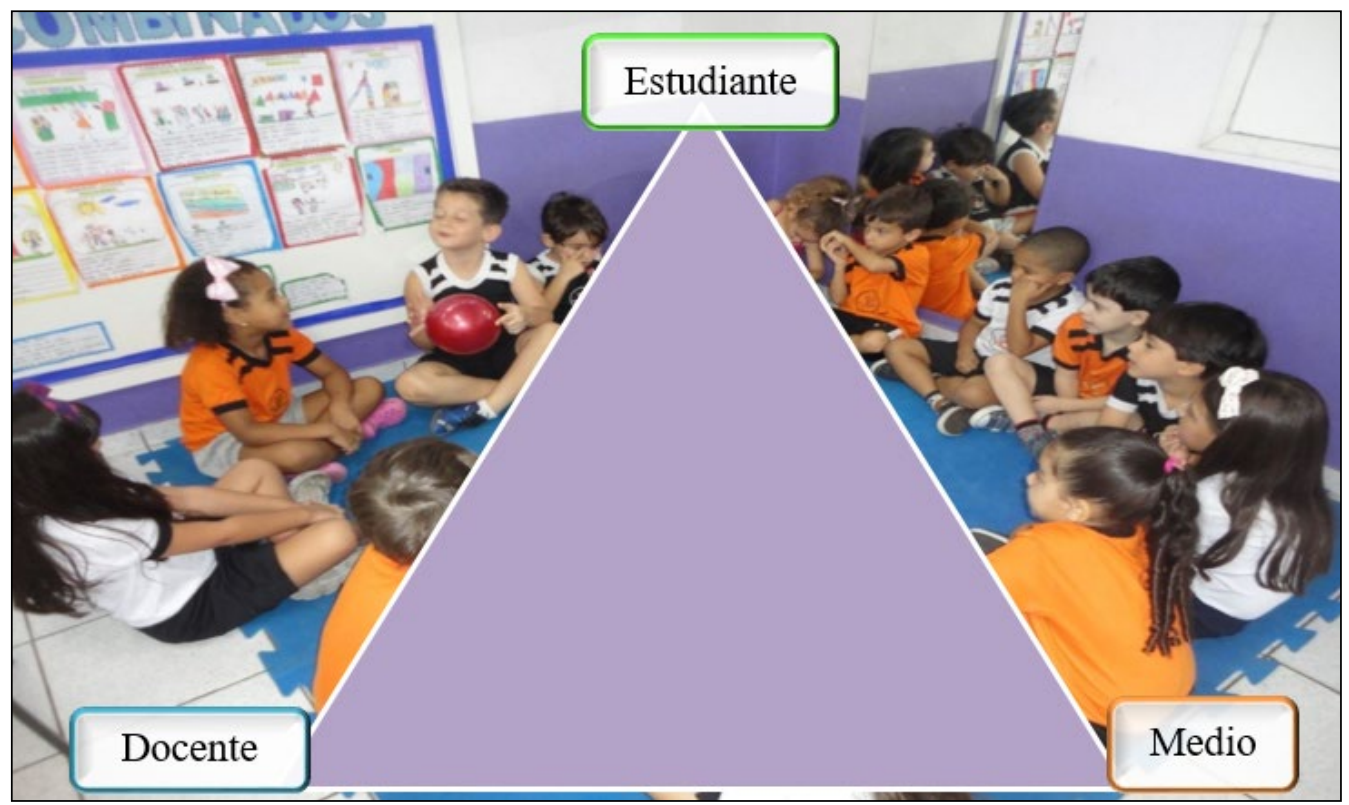

Ese cambio trae algunas consecuencias y apenas una inversión. Esta inversión coloca el estudiante como centro del proceso de aprendizaje, en cuanto al docente asume el papel de facilitador, quien se coloca como observador de la interacción del estudiante con el medio, de esa forma, el medio es preparado por el docente para facilitar al niño el acceso a los saberes y hecha esta preparación el docente se abstrae de interferir. En estas relaciones solo cambian los papeles y ayuda a que se mantenga el proceso piramidal de aprendizaje.

\section{DOS DESAFIOS: LA PERSPECTIVA PROGRESISTA PROBLEMATIZADORA}

Defiendo, a partir de estudios diversos, principalmente de horizonte materialista histórico, otra manera de aprendizaje, donde la pirámide pueda ser sustituida por un proceso dinámico de intercambio de conocimientos, con un enfoque critico interactivo con la realidad y este es circular.

Se trata de una pedagogía que no trabaja con la idea de centro, pero si con la idea de dinamismo del proceso, es circular porque considera que ahora el tema generador surge del medio, ahora surge de los estudiantes y ahora de los docentes. Por ejemplo:

Usted pasa la tarde del domingo preparando su clase, llega el lunes a su comunidad y los estudiantes no quieren hablar del asunto que lleva, ellos quieren hablar de un pleito que aconteció en la comunidad. Ese momento puede ser muy especial o de decepción. De decepción porque usted pasó una tarde entera planeando y ellos no quieren hablar de eso. Sin embargo puede ser un momento 
propicio para trabajar lo que el MINED nos provocó al pensar en el contexto del foro internacional: que pensemos en una oportunidad de trabajar valores, trabajar actitudes, tomar aquella situación y transformar en una oportunidad de aprendizaje. En vez de negar y decir. "No fue para eso que me preparé" y con esta actitud perdimos muchas oportunidades de aprendizajes.

En la figura 4 presento la Pedagogia Dialéctica relacional

Figura 4 -Pedagogía Dialéctica Relacional

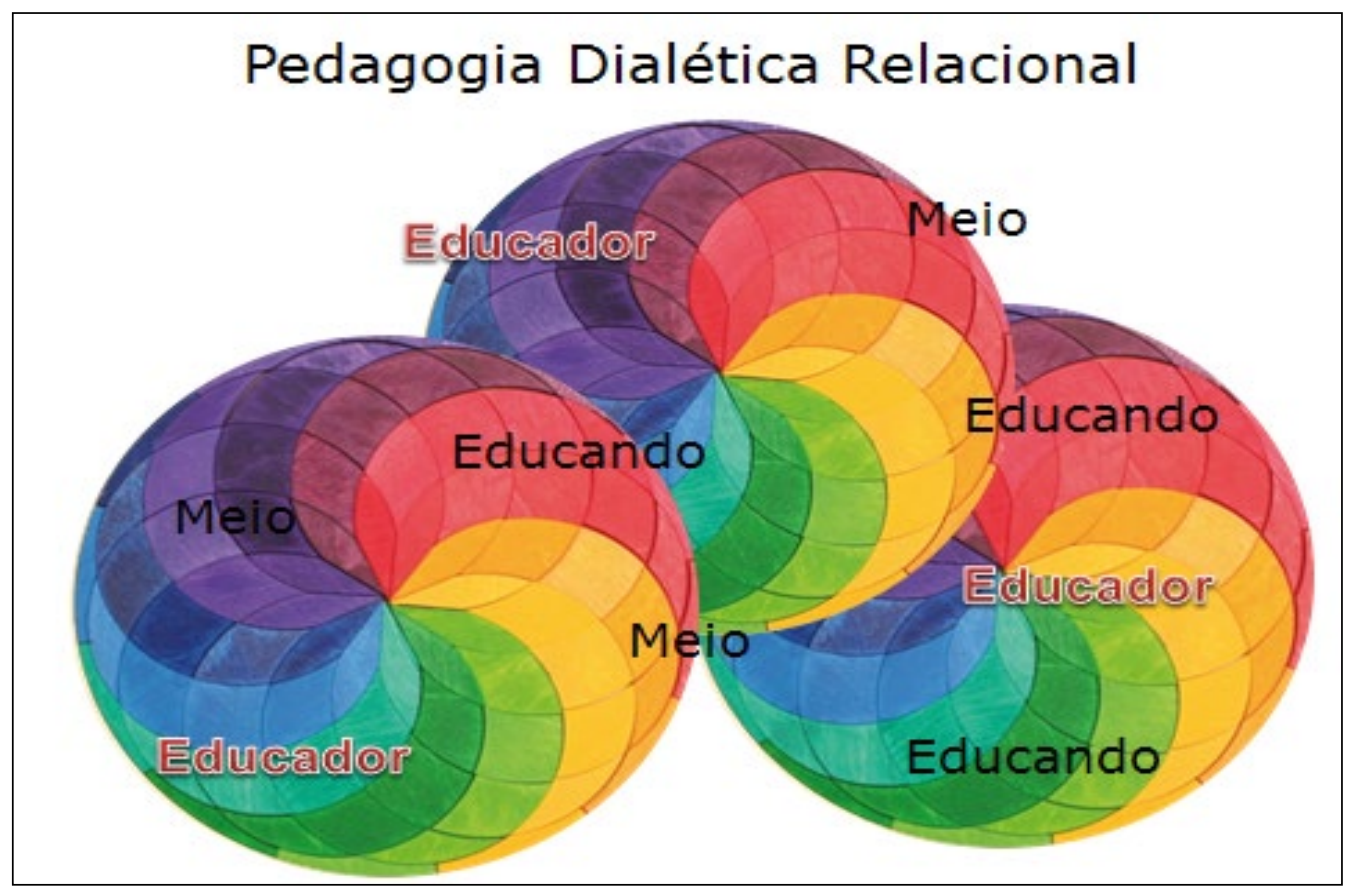

Paulo Freire desarrolló su método, su epistemología a partir de temas generadores. El expone que ahora el tema generador surge del medio, ahora del profesor y ahora del estudiante. Nuestro gran desafío es transformar la temática generadora y un proceso de investigación, porque el tema generador exige interés y consecuentemente desarrollado.

¿Qué es un tema generador? "un universo mínimo temático” (Freire, 2005, p.101), ¿dónde surgen los temas generadores? "Sera a partir de la situación presente, existencial concreta, reflexionando el conjunto de aspiraciones del Pueblo o de la comunidad, que podemos organizar el contenido programático de la educación o de la acción política" (FREIRE, 2005, p. 100).

El tema generador es traído por los estudiantes y por los docentes o puede surgir del medio. Freire sugiere una búsqueda temática en contextos concretos: "el momento de ese buscar es que el diálogo de la educación como práctica de la libertad" (Freire, 2005, p.101) esa investigación implica necesariamente una 
metodología que no puede contradecir el diálogo de la educación libertadora, por tanto debe ser dialógica respetando los diferentes sujetos, Freire cree que no se trata de tener en los hombres objetos de investigación, pero si una comprensión de mundo y lenguaje donde se encuentran insertados e involucrados con sus temas generadores.

Otro desafío de la formación docente según Morín (2007), un gran pensador, nuestro gran desafío es buscar una formación que contemple visiones globalizantes sin olvidar nuestra relación de pertenecen a los contextos prácticos de nuestro mundo de la vida. Pensar globalmente es hacer globalmente. En ese sentido es muy válido su invitación. "pensar globalmente es lo que nos permite una reflexión local. Sin embargo, un abordaje más amplio, que contemple el todo, está fragmentado con la hiperespecialización de los saberes promovidos por la enseñanza” (MORIN, 2007, p. 97)

Creo que, buscando en nuestras memorias, muchos recuerdan cómo eran las clases de los estudios sociales cuando aprendíamos el estudio sobre el universo. Investigábamos galaxias, planetas, continentes, paises y estados, pero nunca llegamos a hablar de nuestro lugar, nuestras memorias en ellas guardadas y apagados por filas y masacrados por el silencio, nos tornábamos apenas oyentes de una historia que no era nuestra, sin oportunidad de manifestar lo que de hecho nos gustaría descubrir. Lo que proponemos con los temas generadores.

Lo que proponemos con temas generadores, como Docente problematizador, es partir del lugar, al final "nuestra comunidad es mayor que el mundo" (BARROS, 2010). Hay un ejemplo en mi ciudad Rio Grande del sur- RS, que es una ciudad costera y tiene problemas sobre la relación del cuidado con las dunas del mar. Una organización creó un proyecto maravilloso de aprendizaje dirigido a la educación ambiental que parte del lugar. El proyecto, olas que te quiero mar parte de un lugar "Balneario Casino", para pensar y establecer perspectivas globales. Sería como, por ejemplo, discutir a partir de la realidad del caribe nicaragüense o desde cada uno de nuestros contextos, como fue contemplado en este foro. Aún en los desafíos considero que tenemos que luchar para superar nuestra forma de construir aprendizajes a partir de visiones estrechas y encogidas que tienen como fin la llamada superespecialización. Morín en su obra Ciencia y Consciencia (2005) afirma que la superespecializaciónes una miopía intelectual. Nos convertimos tan especialista, pero manifestamos grandes dificultades cuando no acercarnos a nuestros pares.

Otro gran desafío consiste en retornaren el proceso de aprendizaje), las cuestiones fundamentales que el currículo no viene contemplando, por ejemplo: lo que significa ser bumano, afectividad, amor, respeto, autoestima, son preguntas básicas no tematizados en nuestras prácticas educativas. Tuve una experiencia de escucha en la Educación de Jóvenes y Adultos y preguntamos a los protagonistas que es lo que ellos más gustan después de haber culminado su año. Ellos respondieron que gustan de muchas cosas, preferencialmente de aquel momento entre cinco o diez minutos, que la maestra detenía su clase y los escuchaba y conversaba con ellos. Después de 
esa escucha me cuestioné sobre cuanto tempo invertimos en contenido, porque tenemos que vencer el contenido sin dejar tempo para escuchar. Otras veces el estudiante nos pide la palabra ¿Puedo hablar con usted? Y respondemos "yo tengo un minuto para Usted". Pensar Educación integral propone la escucha como condición de diálogo. Paulo Freire nos enseña que no es hablando que nosotros aprendemos, pero es escuchando.

Otro desafío muy especial es buscar la formación integral del estudiante. Yo veo eso en la propuesta del Ministerio de Educación de Nicaragua en cuanto horizonte deseado permanentemente. Una Educación que trabaje con valores, ética, estética, política y religión. Creo en esa perspectiva por considerar que la formación en esa perspectiva por considerar que la formación que nos ofrecen es muy limitada. Entonces, ese es un desafío que debe ser permanente, la formación integral. El contexto del III foro internacional tuvo la oportunidad de escuchar de un educador que habló en el salón de clase donde participé en las mesas de trabajo grupales "Que es necesario tener amor en el acto educativo" el amor es una condición fundamental.

Otro desafío para que podamos tener una innovación pedagógica y que sea de hecho creativa y progresista, consiste en reconocer que la realidad es plural y diversa. $\mathrm{Al}$ recordar la enseñanza como paradigma tradicional positivista recordamos que teníamos un grupo con un único método y en aquel contexto y momento, comprendíamos que todos los estudiantes eran iguales. Ahora, nuestro gran desafío consiste en reconocer que nuestro grupo de estudiantes es plural y diverso. Y solamente eso para un docente positivista ya genera una crisis, principalmente, porque cada estudiante es una diferencia. ¿Cómo ser educador reconociendo estas diferencias? Este desafío se tornó mayor aun cuando recibimos en nuestra aula un estudiante con discapacidad. Se trata de otro aprendizaje para nosotros y también para un grupo entero.

Entonces, pensar la Educación en un contexto actual tenemos el desafío de reconocer, por ejemplo, que yo no puedo construir una propuesta educativa a partir de una única idea de familia. Aquella tradicional, padre, madre e hijos. Calma no se asusten. Tenemos que hablar de las familias a partir de una visión plural. En mi ciudad, no existe una escuela pública que celebre el día del padre, ni día de las madres. Celebramos el día de la familia. Eso porque cambió la configuración de la familia ahora el niño vive solo con un miembro de la familia, o con su abuelita, o con su tía; entonces en el paradigma tradicional los niños se sentían muy mal porque en el día de los padres mucho de ellos no los tenían presente. A consecuencia de eso fue una alteración en los documentos pedagógicos cuando hablamos de familias de día de la familia, porque existen muchas configuraciones familiares. No voy a entrar aquíen la discusión de género, que es fundamental para el reconocimiento de la diversidad que tiene mi aula. Creo que no habrá más que cerrar los ojos para darnos cuenta, que la realidad es plural.

Otro asunto o desafío, ya expuesto por los expertos que me antecedieron es la importancia de valorar los contextos y de los diferentes lenguajes que en él existen. Quedo pensando en la riqueza y tuve la oportunidad de conocer la diversidad 
lingüistica y cultural del Caribe nicaragüense, pues debe ser muy especial ser Docente en ese contexto. Conocí a un docente de la Costa Caribe que habla seis idiomas. Pienso cuanto potencial hay en ese contexto favorecido por capital cultural lingüístico. Ese mismo docente me preguntó lo que significa para su pueblo la expresión de Innovación. También reflexionó sobre cómo decir a sus estudiantes este significado. Eso me recuerda a lo que Paulo Freire afirmó "enseñar exige un profundo respeto a los saberes y la cultura de mis estudiantes"

Otro cambio y desafío fundamental es que no podemos trabajar en el siglo XXI la perspectiva anunciada que establece relación sujeto - objeto. Teniendo como fin superar esa querella defendemos las relaciones intersubjetivas. Por ejemplo. Orienté una investigación a un estudiante de maestría durante dos años, quien trabajó con lenguaje en círculos de conversaciones en la educación infantil. Muchas veces los padres que iban a buscar a sus hijos a la escuela le preguntaban. ¿Qué está haciendo? Ellos no tienen nada que decir para quedar sentado en círculos. Sin embargo, el trabajo fue muy enriquecedor por la cantidad y calidad de informaciones sobre el lenguaje infantil que surgió de esa práctica.

En otra ocasión tuve acceso a una investigación sobre aprendizajes infantiles en los momentos de soledad. Ese estudio demostró que los niños en sus relaciones cotidianas presentan, discuten y resuelven problemas. También crean consensos colectivos, todas las veces que los niños estaban en proceso de resolver el problema, llegaba un adulto y acababa con la negociación y el entendimiento que allí estaba siendo construido. Eso ocurre muchas veces por el hecho de que el adulto (que se concibe como sujeto) ignora las potencialidades lingǘsticas y creatividad de los niños y niñas que también son sujetos.

Aun en los desafíos he realizado estudios en el campo de la filosofía, principalmente del filósofo Habermas (1999), que definiendo la existencia de un nuevo paradigma denominado post metafísico sugiere que debemos de pensar en la superación de la relación distante entre teoría y práctica. El considera que mi teoría ya tiene una práctica; ejemplo. Yo digo a mis estudiantes que prometo que desarrollaré una clase especial. Ellos ya imaginan la acción. Discurso y práctica están muy próximos.

Otro desafío nos invita a pensar seriamente sobre quiénes son los sujetos que nosotros estamos educando. Percibí que el Pueblo de Nicaragua es muy religioso. En este sentido, como educador puedo o no creer lo que veo y percibo de las manifestaciones religiosas. Mi obligación es respetar y reconocer que para esos niños que educo la dimensión religiosa es fundamental y que posee mucho sentido en sus vidas. 
Desarrollé un estudio en Brasil denominado Ecología Cosmocena, la redefinición del espacio humano como un ser biopsicossocioambiespiritual. Eso consiste en considerar que somos seres con múltiples dimensiones y ese ser que Usted está educando, también su alma. Por tanto, el acto educativo moviliza toda la vida y esto significa pensar en educación integral. Los modelos de enseñanza tradicional nos fragmentan, pero tenemos desafíos de pensar el ser de manera integral. Lo que implica que nuestro compromiso como educadores debe de ser mayor.

Por eso en mi exposición el primer día del foro recordé el compromiso de educar a partir de la constatación que mi presencia y la presencia de los docentes jamás pasa desapercibida frente a nuestros estudiantes. Y ella ayuda o desayuda en la formación y en su vida. Qué compromiso, que responsabilidades tenemos. Pero también que desafío y que oportunidad.

\section{PALABRAS FINALES}

El ejercicio de pensar el tiempo, de pensar la técnica, de pensar el conocimiento de cuánto se conoce, de pensar el que de las cosas, el para qué, el cómo, en favor de qué, de quién en contra de que, o en contra de quién son exigencias fundamentales de una Educación democrática a la altura de los desafíos de nuestros tempos.(FREIRE, 2000, p. 102).

En el momento en que escribo este texto cargado de reflexiones y problematizaciones mi mente viaja hasta mi lugar, mi país, donde se vive un tiempo donde la reflexión sobre el propio tiempo es necesaria, conviene resaltar que en mi país muchos docentes después de haber vividos muchos avances y muchas prácticas progresistas cargadas de sentidos y de transformación social dirigida a la emancipación, tenemos que convivir trágicamente con una situación de golpe que utiliza estrategias que buscan limitarlos. A constitución los describo:

- El movimiento Escuela Sin Partido, que intenta cohibir cualquier manifestación de formación crítica y política en la escuela, es antagónico y limitador de potencialidades educativas. Cuando Freire retornó del exilio, él afirmaba que era necesario después de la dictadura que teníamos que reaprender el país. Consideramos que después del reciente golpe vivido en Brasil es necesario que estudiemos una vez, más esa cara de opresor. Se hace necesario el ejercicio de dos categorías promovidas por el diálogo: reaprender y resistir. En ese contexto actualmente en nuestro país nos esforzamos en demostrar que eso es posible, a fin de vencer cualquier tentativa de subordinación. Vivimos un tiempo en que conocemos bien las marcas de ser oprimido, restudiemos la Pedagogía del opresor que podamos dialogar en contra de la escuela sin partido fundamentada en la "Ley de la

7 Utilizaré partir de ahora a palabra biopsicossocioambiespiritual aún no registrado en los diccionarios considerando que expresa una comprensión cosmocena de aquello que constituye la humanidad. Por eso juntarlos em uma sola terminologia agrega las dimensiones biológicas, psicológica, sociológica, ambientales e espirituales. 
Mordaza”. Estos elementos refuerzan que el pensamiento de Paulo Freire, a veinte años de su tránsito a la inmortalidad, nos sirve como referencia para una pedagogía de la contra marcha como Capacidad de Resistencia en los actuales tiempos de nuestro Brasil.

- Las politicas neoliberales direccionadas de los Estados Unidos de América poseen un gran impacto en el encogimiento de las garantías conquistadas en los últimos años tanto en el ofrecimiento de nuevas directrices que interfieren directamenteen las políticas educativas.

- Brasil vive una fusión de acuerdos, directrices, resoluciones y parámetros curriculares que están insertas en un amplio movimiento de reformas neoliberales que vienen siendo desarrolladas en América Latina y poseen como eje expandirlas en la educación primaria.

- Uso de campañas, legislaciones y libro didáctico como instrumento de inhibición y despolitización del quehacer pedagógico;

Diferente a eso la experiencia que presencié por el Gobierno de Nicaragua cargada de protagonismo, demuestra que en este momento este País tiene una gran democracia y tiene una propuesta de Educación asociada con un proyecto de nación en la búsqueda de ampliación de derechos dentro de ellos "La educación" estos momentos presentan fuertes indicadores de una educación problematizadora - libertadora y por consecuencia humanizadora.

Quiero reforzar que esa experiencia con gran protagonismo sirve de referencia positiva y de orientación para tantas naciones que cayeron en el canto de la sirena de la lógica neoliberal. En ese sentido 20 años después su muerte de Paulo Freire revive en tierras nicaragüenses.

\section{REFERENCIAS}

BARROS, M. de. O Livro das Ignorãças. In: BARROS, Manoel de. Poesia Completa. São Paulo: Le Ya, 2010. pp. 297-324.

BECKER, F. A epistemologia do professor. Petrópolis: Vozes, 1993.

FREIRE, P. Pedagogia da autonomia. 14 ed. São Paulo: Paz e terra, 2000.

FREIRE, P. Política e Educação. São Paulo: Cortez, 1993.

FREIRE, P. Pedagogia da Esperança: Um reencontro com a pedagogia do oprimido. Rio de Janeiro: Paz e Terra, 1992.

FREIRE, P. Pedagogia do oprimido. Rio de Janeiro: Editora Paz e Terra, 2011.

FREIRE, P. Educação e Mudança. Rio de Janeiro: Paz e Terra, 1979.

FREIRE, P. Educação como Prática da Liberdade. Rio de Janeiro: Paz e Terra, 1971.

FRIGOTTO, G. "Escola sem partido": imposição da mordaça aos educadores.

Disponível em: < http:/ /www.pagina13.org.br/educacao-2/escola-sem-partidoimposicao-da-mordaca-aos-educadores/> acessado em: 11/10/2016. 
FRIGOTTO, G. Escola Sem Partido: esfinge que ameaça a educação e a sociedade brasileira. Rio de Janeiro: UERG, 2017.

GONÇALVES V. R. S. da, da CARVALHO, da S, A. I. Os desafios da implementação das diretrizes curriculares nacionais para a formação de professores no Brasil Rev. Eletrônica Mestr. Educ. Ambient. E-ISSN 1517-1256, Edição especial XIX Fórum de Estudos: Leituras de Paulo Freire, p. 126-141, junho, 2017.

HABERMAS, J. Pensamento pós-metafísico. Tradução: Flávio Beno Siebeneichler. Rio de Janeiro: Tempo Brasileiro,2002.

LIBÂNEO, J. C. Democratização da escola pública: A pedagogia crítico-social dos conteúdos. $2^{\text {a }}$ ed. São Paulo: Edições Loyola, 1985.

MORIN, E. Os setes saberes necessários à educação do futuro. Tradução de Catarina Eleonora F. Silva e Jeanne Sawaya. São Paulo: Cortez, 2007.

PEREIRA, V.A, RINALDI, G, da R. A atualidade da categoria Diálogo em Freire em tempos de "Escola sem partido". Disponível em: < https:/ /www.seer.furg.br/ remea/article/viewFile/6895/4518> Acesso em 22/08/2017.

PEREIRA, V. A; DIAS, LIMA, J.R; TELMO, B.P. Educação Popular e a Pedagogia da Contra Marcha: uma homenagem a Gomercindo Ghiggi. 1. ed. Passo Fundo: Méritos, 2013.

PEREIRA, V. A. Ecologia Cosmocena: a redefinição do espaço humano no cosmos. Juiz de - Fora, MG: GARCIA edizioni, 2016.

PEREIRA, V. A.(org). Hermenêutica \& Educação Ambiental no contexto do Pensamento Pós-Metafísico. Juiz de-Fora, MG: GARCIA edizioni, 2016.

SAVIANI, D. Escola e democracia: teorias da educação, curvatura da vara, onze teses sobre educação política. 32ª ed. Campinas: Autores Associados, 1999.

SUCHODOLSKI, B. A pedagogia e as grandes correntes filosóficas: a pedagogia da essência e a pedagogia da existência. 4ª ed. Lisboa: Livros Horizonte, 1992.

VEIGA, I. P. Projeto Político Pedagógico da Escola: uma construção possível.

Campinas SP: Papirus, 1995. 